\section{Post exertional headache}

I was interested in the report of GarciaAlbea et al on post exertional headache ${ }^{1}$ but they should not include footballers' migraine in this category. This is triggered, not by running about the field, but by blows to the head, either in heading the ball orin the more robust form of the gameplaying scrum half. ${ }^{2}$

WB MATTHEWS St Edmund Hall Oxford, UK

1 Garcia-Albea E, Cabbrera F, Tejeiro J, Jimenez-Jimenez F-J, Vaquero A. Delayed postexertional headache, intracranial hypotension and racket sports. $\mathcal{f}$ Neurol Neurosurg Psychiatry, 1992;55:975.

2 Matthews WB. Footballers' migraine. $B M F$ 1973;2:326-7.

\section{NOTICE}

International Congress on Stroke Rehabilitation in Berlin, 21-24 November 1993. The meeting will be organised by the German Society for Neurological Rehabilitation in collaboration with several European Societies for rehabilitation. Further information from: DER Congress, Congress Organisation, Bundesallee 56, D-1000, Berlin 31, Germany. Tel: ++49 30 85 7903-0, Fax: ++49 3085 7903-26.

\section{BOOK REVIEWS}

Handbook of Neuroradiology (a Mosby Year book). By ANNE G OSBORN (Pp 411; Price: $£ 27.00)$. 1991. London, Wolfe Publishing Ltd. ISBN 0-8151-6578-1.

I have long been searching for a small textbook that will solve all my neuroradiological diagnostic dilemmas; or at least provide a sensible differential list when I realise "I have never seen one of those before". Such a book does not exist but Dr Osborn's work goes some way to answering this need.

The 400 pages are essentially a collection of lists. My main concern is that the subheadings are poorly identified. If they were in heavy type, or underlined, the book would be much easier to use. At first sight it appears similar to a number of texts that are aimed at trainee radiologists preparing for their final professional examination. In reality it is much more than this and will be of value to trained neuroradiologists and to clinicians working in related fields. There are excellent sections on normal anatomy and variants, and abnormal brain development Disease processes are arranged by anatomical location. There is an appropriate emphasis on the MR appearance of various pathologies.
Each section has a useful summary and a short list of references. I have a few quibbles, such as the poor classification of spinal vascular abnormalities. It is reasonable value at $£ 27$. If I wore a white coat I would give this book pride of place in a pocket. That is a considerable accolade.

RICHARD JV BARTLETT

Neurologic Differential Diagnosis/2nd Edition. (Translated and annotated by Otto Appenzeller). By MARK MUMENTHALER. (Pp 178; Illustrated; Price: DM68,00.) 1992. Stuttgart, G. Thieme Verlag. ISBN 3-13-6655002-6.

In a somewhat philosophical preface to the second edition of "Neurologic Diagnosis", Otto Appenzeller describes the book as a "timely addition to the training of clinical neurologists", bemoaning, not without amusing hyperbole, the retreat of clinical skills in the face of a growing public knowledge and awareness of the advantages of "neurodiagnostic testing". He refers to the trend towards defensive medicine and the relative security of the "report" and hence the over-investigation on the neurological patient. This is a timely and well considered warning.

The book itself, translated from the original German by Otto, is the second edition of Mark Mumenthaler's original script and, I feel, does achieve its aim to "show how best to arrive at a diagnosis, and judiciously to employ the support of neurodiagnostic investigation".

The text is supported by some very good illustrations and a leavening of neuroanatomical and neuropathological correlation Perhaps the format is a little "dated", but none the worse for that.

J B FOSTER

Neural Transplantation: A Practical Approach Series. Edited by $\mathrm{S}$ B DUNNETT and A BJORKLUND. (Pp 211; Illustrated; Price: £19.50.) 1992. Oxford University Press. ISBN 0-19-963285-5 (p/b)

This brief 200 page manual edited by two of the pioneers in the field distils the wisdom of 20 years practical experience. The experimental techniques are presented for "any neuroscientist who wishes to use neural transplantation in his or her own laboratory". There are Chapters on Staging and dissection of rat embryos (the editors); Grafting genetically modified cells (Gage and colleagues); Neural transplantation in adult rats (the editors); Intracerebral transplantation to immature hosts (Lund and Yee); Peripheral nerve grafts to study CNS regeneration (Aguayo and colleagues); Transplantation of glia to spinal cord (Blakemore and Crang); Neural transplantation in primates (Annett and Ridley); Human embryonic tissue (Brundin); Immunology (Lund and Baneriee); Identifying grafted cells (Cadusseau and Peschanski). An appendix provides information on suppliers of specialist items. The text is liberally illustrated, and practica protocls with essential detail are provided throughout. A "must" for anyone entering the field, and an invaluable bench mark of best technique for those already engaged in this exciting area of neuroscience.

C D MARSDEN
Autonomic Failure: A Textbook of Clinical Disorders of the Autonomic Nervous System/Third Edition. Edited by SIR ROGER BANNISTER and CHRISTOPHER J MATHIAS. (Pp 953 Illustrated; Price $£ 95.00$.) 1992. Corby, Oxford Medical Publications. ISBN 0-19-262219-6.

Sir Roger Bannister concluded the preface to the first edition of his book with the words of his teacher, Sir George Pickering, that it was 'in fact no more than an overture. The main body of the work is to come.' This third edition is a revision of the second edition with 20 new chapters from worldwide authors, and illustrates that prophecy.

The editors and authors have succeeded in compiling an excellent comprehensive volume on the autonomic nervous system including genetics, molecular biology, anatomy, investigations and diseases which, despite its multi-authorship, avoids the problem of repetition and shows the editors' knowledge and experience of the assessment of patients with autonomic failure. There are important practical points about testing autonomic disorders such as the time which should be taken to assess maximal contraction of the pupil with pilocarpine in the Adie syndrome and the value of urodynamic assessment, together with an excellent critique of the interpretation and validity of the commonly used clinical tests.

The volume is well balanced with an emphasis on diabetic autonomic failure, autonomic dysfunction in peripheral nerve disease, and the association of autonomic failure with extrapyramidal syndromes. Though the chapter on dopamine betahydroxylase deficiency seems disproportionately lengthy, it is justified by the important genetic and molecular biochemical models which it provides, and reflects the interest of the editors. The final section on disorders affecting autonomic function involving syncope and fainting, cardiac dysrhythmias and hypertension illustrates the implications of the autonomic nervous system in medical practice and assures a wider readership than clinical neurology alone.

The publishers are to be congratulated on the fact that, despite is formidable size (over 940 pages), the book easily remains open at the requisite page when placed on a desk and avoids constant struggling to find, or keep, one's place.

DAVID BATES

Handbook of Amytrophic Lateral Sclerosis (Neurological Disease and Therapy Series/12). Edited by RICHARD ALAN SMITH. (Pp 783 Illustrated; Price: $\$ 195.00$ (US and Canada). \$224.25 (All Others)). 1992. New York, Marcel Dekker Inc. ISBN 0-8247-8610-6.

The exponential increase in the number of papers and books on motor neurone diseases in the last decade reflects the realisation that this devastating disease represents a major unresolved problem. Fifty-two authors, 38 of them from the USA, contribute to the 31 chapters. The material is organised in two major sections: Diagnosis and Management and Research Strategy. The first takes the initial 318 pages, the second the remaining 436 pages of text.

Most research lines into the aetiopathogenesis are covered. Some of the basic science 